\title{
Recent Trends in Studies on Botanical Fungicides in Agriculture
}

\author{
Mi-Young Yoon ${ }^{1}$, Byeongjin $\mathrm{Cha}^{2}$ and Jin-Cheol Kim ${ }^{1 *}$ \\ ${ }^{I}$ Eco-friendly New Materials Research Group, Division of Convergence Chemistry, Korea Research Institute of Chemical \\ Technology, Daejeon 305-600, Korea \\ ${ }^{2}$ Department of Plant Medicine, Chungbuk National University, Cheongju 361-763, Korea \\ (Received on May 31, 2012; Revised on October 22, 2012; Accepted on November 2, 2012)
}

\begin{abstract}
Plants are attacked by various phytopathogenic fungi. For many years, synthetic fungicides have been used to control plant diseases. Although synthetic fungicides are highly effective, their repeated use has led to problems such as environmental pollution, development of resistance, and residual toxicity. This has prompted intensive research on the development of biopesticides, including botanical fungicides. To date, relatively few botanical fungicides have been registered and commercialized. However, many scientists have reported isolation and characterization of a variety of antifungal plant derivatives. Here, we present a survey of a wide range of reported plant-derived antifungal metabolites.
\end{abstract}

Keywords : antifungal activity, botanical fungicide, plantderived metabolites, plant diseases

For many years, plant pathogenic fungi have caused devastating losses worth millions of dollars in crops worldwide. Synthetic fungicides have effectively controlled plant pathogenic fungi. Their repeated use over decades has disrupted natural biological systems, and sometimes resulted in development of fungal resistance. They had undesirable effects on non-target organisms, and fostered environmental and human health concerns. Therefore, alternative measures have been developed for crop protection. In an attempt to reduce the use of synthetic fungicides, intensive investigations into the possible exploitation of biopesticides such as natural commercial products that are safe for humans and the environment have been undertaken.

The global pesticide market was valued in 2009 at about $\$ 42.8$ billion. Of that total, nearly $3.74 \%$ is attributable to biopesticides. The global pesticide market is expected to expand further through 2014 for both synthetic pesticides and biopesticides. However, it is estimated that the use of synthetic insecticides will continuously decline, particularly in response to the momentum of organic agricultural practices,

\footnotetext{
*Corresponding author.

Phone) +82-42-860-7436, FAX) +82-42-861-4913

E-mail)kjinc@krict.re.kr
}

use of integrated pest management (IPM), and the development of genetically modified (GM) seeds with insecticidal qualities. The synthetic pesticide market comprises herbicides, fungicides, insecticides, and others, accounting for $48 \%, 26 \%, 16 \%$, and $10 \%$ of the total market, respectively. The pesticide market was declined over the period 1999 to 2004 because of the development of biopesticides and GM crops, especially herbicide-resistant seeds. However, in 2005, the use of herbicides began to increase, partly in response to the increased aggressiveness of herbicide-resistant weeds, the development of "super" weeds, and the expansion of sales to new markets. Currently, the annual growth rate of synthetic pesticides is estimated to be $3 \%$ for the period 2009 to 2014. In contrast, the annual growth rate of biopesticides over the same period is expected to be $15.6 \%$. The percentage of the total pesticide market for biopesticides is expected to increase to around $6 \%$ by 2014 .

In USA, there are currently more than 245 registered biopesticide-active ingredients used in hundreds of products. Biopesticides are classified into microbial pesticides, biochemical biopesticides, plant incorporated protectants (PIPs; GM organisms or crops), predators, entomopathogenic nematodes, and parasitoids. Biopesticides account for about $20 \%$ of all pesticide-active ingredients registered in USA.

In Korea, a total of 33 biopesticides are registered, of which 19 are fungicides; 13 , insecticides; 1 , herbicide. Most of them are microbial pesticides; only 2 of 33 are botanical pesticides, which consists of 1 herbicide and 1 insecticide. No botanical fungicide has been registered in Korea.

In general, biopesticides are classified as natural products (microorganism-derived, higher plant-derived, and animalderived products) and microorganisms (viruses, bacteria, fungi, nematodes, and protozoa) (Copping and Menn, 2000). However, of the natural products, microorganism-derived compounds are not generally accepted as biochemical biopesticides in Korea, where they are recognized to be almost the same as synthetic pesticides. Therefore, many Korean scientists have been focused on the development of natural pesticides from plant-derived compounds. Research on botanical fungicides for agriculture has been intensified, since it has become evident that botanical fungicides have 
enormous potential to inspire and influence on modern agrochemical research. The development of botanical fungicides would help decrease the negative impacts of synthetic agents, such as residues, resistance, and environmental pollution. In this respect, botanical fungicides may be effective, selective, biodegradable, and less toxic to the environment. In this paper, we reviewed commercially available plant-derived fungicides and various antifungal metabolites that show potent in vivo antifungal activities and have not yet been introduced into the market.

\section{Cinnamaldehyde}

Cinnamaldehyde (1; Fig. 1) was isolated from cinnamon essential oil in 1834 by Dumas and Peligot and synthesized in the laboratory by Chiozza in 1854 . The chemical is usually synthesized for crop protection. It is effective against dry bubble caused by Verticillium fungicola, dollar spot caused by Sclerotinia homeocarpa, and pitch canker disease caused by Fusarium moniliforme var. subglutinans (Copping, 2004). Wang et al. (2005) reported antifungal activity of essential oils and their constituents from indigen- ous cinnamon (Cinnamomum osmophloeum) leaves against wood decay fungi. Compared to the other components, cinnamaldehyde, the major compound in C. osmophloeum leaf essential oils, possessed the strongest antifungal activities and showed $100 \%$ efficacy against both Coriolus versicolor and Laetiporus sulphureus. Cheng et al. (2008) reported the antifungal activity of cinnamaldehyde and eugenol congeners against wood-rot fungi. Results from antifungal tests revealed that cinnamaldehyde, alpha-methyl cinnamaldehyde, $(E)$-2-methylcinnamic acid, eugenol, and isoeugenol exhibited strong antifungal activity against all fungi tested. Moreover, Khan et al. (2011) evaluated the effects of cinnamaldehyde, eugenol, citral, and geraniol on growth, hyphal ultrastructure, and virulence factors of Aspergillus fumigates and Trichophyton rubrum. The antifungal activity of their major constituents was evaluated in order cinnamaldehyde $>$ eugenol $>$ geraniol $>$ citral.

The mode of action of cinnamaldehyde is not understood. Its low toxicity and well-known properties make it ideal for agriculture. Cinnamaldehyde is sold as a $30 \%$ wettable powder (WP) formulation, which named Vertigo Wettable Powder Fungicide (Monterey), and cinnacure A3005 (Pro-<smiles>O=C/C=C/c1ccccc1</smiles>

(1)<smiles>COCCC(N)CO</smiles>

(2)<smiles>NCCCC(=O)O</smiles>

(3)

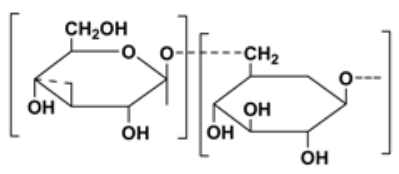

(4)

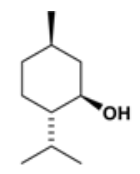

(5)

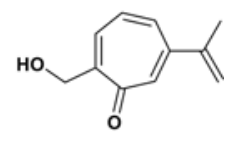

(6)

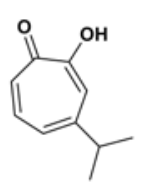

(7)<smiles>O=Cc1cccc(=O)c(O)c1</smiles>

(8)

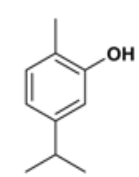

(9)<smiles>Cc1ccc(C(C)C)c(O)c1</smiles>

(10)<smiles>Cc1ccc(C(C)C)cc1</smiles>

(11)<smiles>CCCC(=O)O</smiles>

(12)<smiles>CCCCCC(=O)O</smiles>

(13)

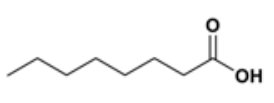

(14)

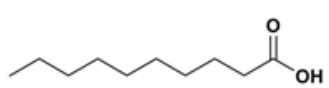

(15)

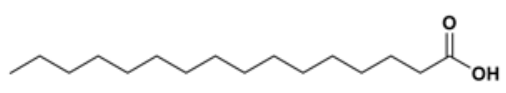

(18)

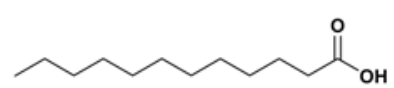

(16)

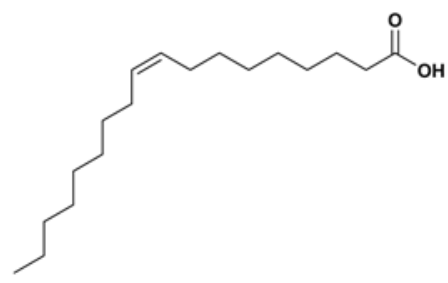

(19)

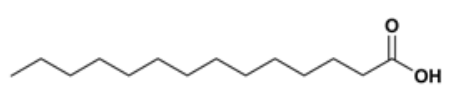

(17)

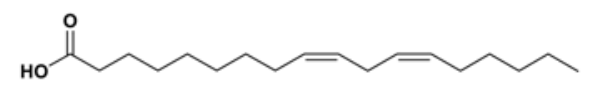

Fig. 1. Chemical structures of various plant-derived antifungal metabolites. 
Recent Trends in Studies on Botanical Fungicides in Agriculture

3

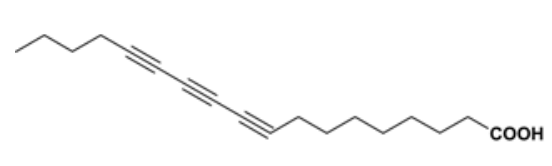

(21)

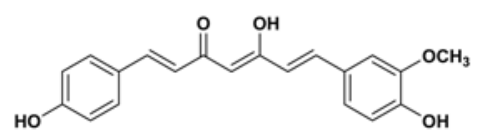

(24)

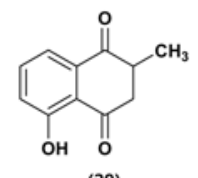

(29)

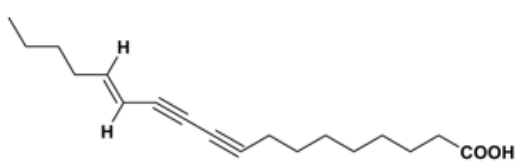

(22)

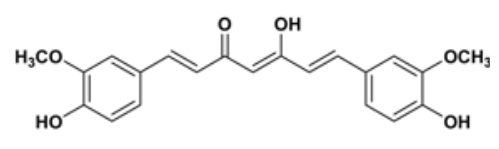

(23)
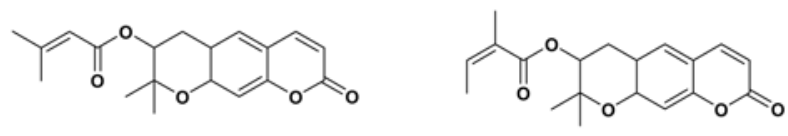

(34)

(35)

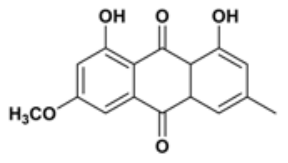

(31)

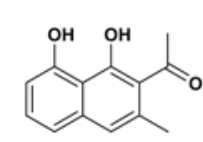

(32)

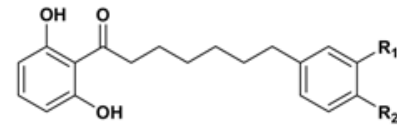

(26): $R_{1}=R_{2}=H$

(27): $\mathrm{R}_{1}=\mathrm{H}, \mathrm{R}_{2}=\mathrm{OH}$

(28): $\mathrm{R}_{1}=\mathrm{R}_{2}=\mathrm{OH}$

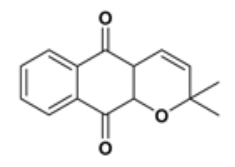

(33)

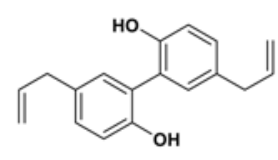

(39)

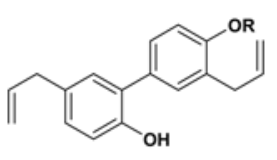

(40): $\mathrm{R}=\mathrm{H}$

(41): $\mathrm{R}=\mathrm{CH}_{3}$

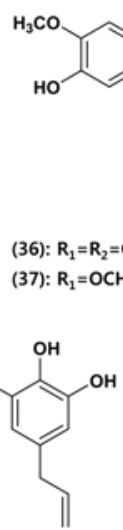

(42)

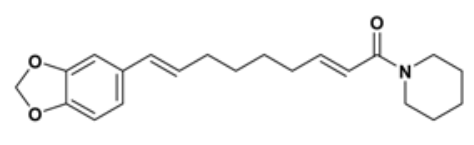

(43)

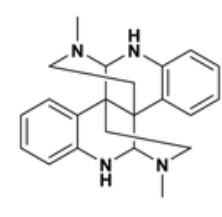

(44)

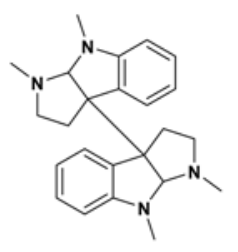

(45)
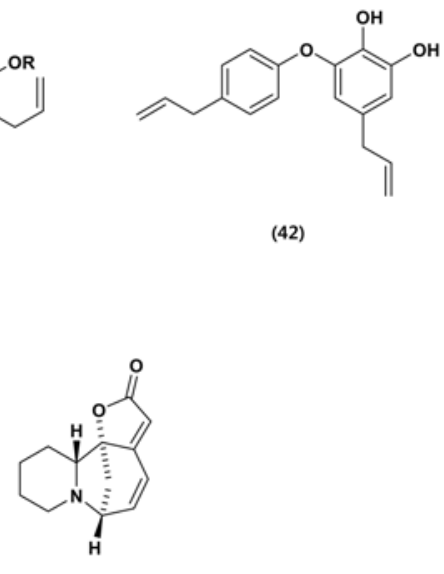

(46)<smiles>COc1cc(O)cc(C2OC(c3ccc(O)c(OC)c3)C(C)C2C)c1</smiles>

(38)
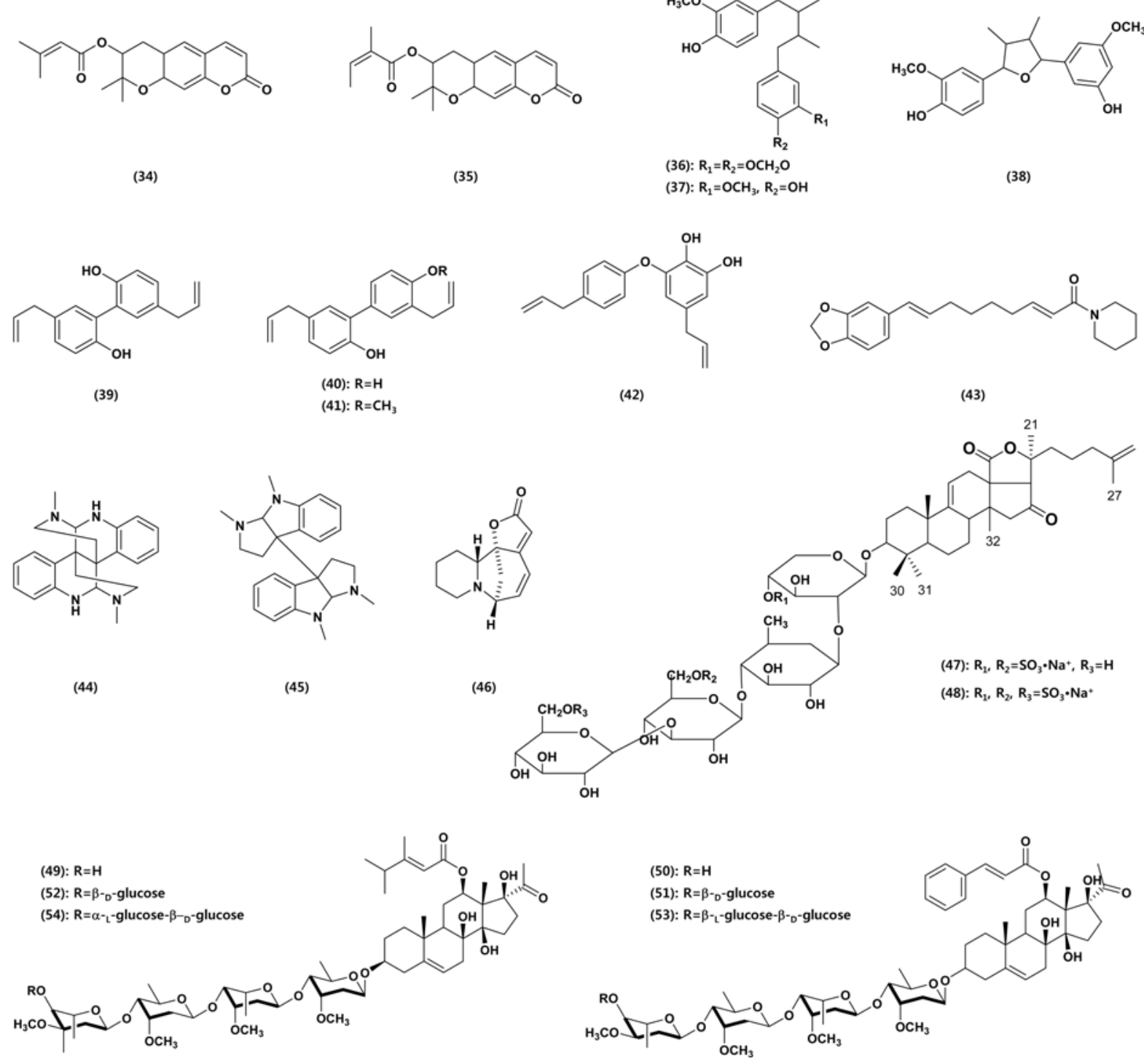

Fig. 1. Continued 
guard). It is not soluble in water and is degraded rapidly in the soil and is not expected to pose any hazard to non-target organisms or the environment.

\section{L-Glutamic acid + gamma-aminobutyric acid}

Gamma-aminobutyric acid (GABA) (2) (29.2\%) and Lglutamic acid (29.2\%) are found in all living organisms. Lglutamic acid (3) is a major amino acid naturally found in plant and animal proteins, and GABA helps to maintain normal brain function. These two ingredients enhance the growth of specified plants such as almond, broccoli, and onions, prevent development of powdery mildew on grapes, and suppress certain other plant diseases such as brown rot (Monilia sp.) and shot hole (Stigmina carpophila) of stone fruit (Copping, 2004). The products are applied by spraying, drenching the soil, or via particular irrigation systems. Toxicity tests in animals and humans did not show any adverse effects from GABA or L-glutamic acid. Both substances occur naturally in plants and animals. Products containing the two substances are not approved for direct application to water or to areas where surface water is present.

\section{Jojoba oil}

Jojoba oil is a vegetable oil obtained from the jojoba bean. The physical properties of jojoba oil are similar to those of other vegetable oils. Jojoba has been found to be very effective and capable of controlling white flies and powdery mildew on ornamental plants and grapes. The ability of jojoba oil to remain stable even at high temperatures make it a widely usable fungicide in nearly all climatic conditions. One of its mechanisms of action is to form a physical barrier between an insect pest and the leaf surface (Copping, 2004). The fungicide is applied by ground application like a spray containing a final concentration of $\leq 1 \%$ jojoba oil.

\section{Laminarin}

Laminarin (also known as laminaran) (4) is a storage glucan (a polysaccharide of glucose) found in the blue green algae Laminaria digitata. Generally, $\beta$-glucans are major constituents in the bran of most cereal grains and intentionally added to many dietary supplements and texturing agents. It induces defense reactions in agricultural crops such as fruiting vegetables, including tomato, eggplant, pepper, zucchini, cucurbits, watermelon, melons, grape, apple, and pear. In particular, laminarin efficiently elicits defense responses in grapevine plants against gray mold and downy mildew caused by Botrytis cinerea and Plasmopara viticola, respectively. The development of these pathogens in infected grapevine plants was effectively sup- pressed by laminarin, and its application reduced infection by $B$. cinerea and $P$. viticola by approximately $55 \%$ and $75 \%$, respectively (Copping, 2004). Liangbin et al. (2012) reported inhibitory effects of laminarin on the growth and toxin production of A. flavus. Significantly, inhibition of aflatoxin production in Sabouraud liquid medium was achieved using $150 \mu \mathrm{g} / \mathrm{ml}$ and $200 \mu \mathrm{g} / \mathrm{ml}$ of laminarin, without affecting mycelium growth. A natural fungicide containing laminarin is registered for use on wheat to control powdery mildew.

\section{Milsana}

Milsana is an ethanol extract from the plant Reynoutria sachalinensis for use on greenhouse-grown plants. Its application helps reduce certain plant diseases. Milsana is generally used as a preventative rather than a curative application, and the principal target disease is powdery mildew. Milsana controls powdery mildew on wheat by a combination of induced resistance and direct antifungal activity. A single spray to run-off, $48 \mathrm{~h}$ before inoculation, reduced mildew infection on young glasshouse seedlings by $97 \%$ (Reglinski, 2009). The active ingredient appears to be a natural elicitor of phytoalexins, which induce the plant's natural "immune system" and resistance in the host plant (Copping, 2004). Konstantinidou-Doltsinis et al. (2006) reported the effects of $R$. sachalinensis extract and Milsana on conidial germination of Leveillula taurica and the efficacy of both Milsana formulations (Milsana WP 1999 \& 2001) against the pathogen in the greenhouse. In addition, the research group reported field efficacy of 2 formulations of $R$. sachalinensis extract against powdery mildew (Uncinula necator) in grapes.

\section{Pink plume poppy powder extract}

Macleaya cordata is a bloodroot that has been used as an oriental medicine in China. Its extract contains sanguinaine and chelerythrine, which have fungicidal and insecticidal activities. Liu et al. (2009) reported that isoquinoline alkaloids from $M$. cordata were active against plant microbial pathogens. Among sanguinarine, chelerythrine, protopin, and alpha-allocryptopin isolated from $M$. cordata, sanguinarine displayed a significant antifungal activity against Rhizoctonia solani with a median inhibitory concentration $\left(\mathrm{IC}_{50}\right)$ of $0.45 \mu \mathrm{g} / \mathrm{ml}$. Its crude extract and individual alkaloids are also active against several human pathogenic bacteria (Kosina et al., 2010). The extract from M. cordata capsules had stronger antimicrobial effect than that from the aerial part of the plant or seeds and is sold as a $1.5 \%$ aqueous solution (Camas) (Copping, 2004). Even though the mode of action has not been confirmed, the commercial product is known to induce systemic acquired resistance through accumu- 
lation of endogenous phenolic substances in the treated plants. This extract is a naturally occurring substance and is not considered to be toxic to non-target organisms, does not cause adverse environmental effects (Copping, 2004).

\section{Essential oils}

The essential oil from cymbopogan exhibited control values over all the plant and food rot mold tested (Soundharrajan et al., 2003). Edris and Farrag (2003) reported antifungal activities of essential oils of peppermint and sweet basil and their major aroma constituents in the vapor phase on some plant pathogenic fungi, such as S. sclerotiorum, Rhizopus stolonifer, and Mucor sp. Menthol (5) was found to be the individual aroma constituent responsible for the antifungal properties of peppermint essential oil, while menthone alone did not show any effect at the doses tested. In the case of basil oil, linalool alone showed a moderate antifungal activity while eugenol was completely inactive. However, mixing the two components in a ratio similar to their concentrations in the original oil was found to enhance the antifungal properties of basil oil, indicating a synergistic effect. Morita et al. (2004) reported clear antifungal activity of $\beta$-dolabrin (6), $\gamma$-thujaplicin (7), 4-acetyltropolone (8), and hinokitiol-related compounds against plant pathogenic fungi. In particular, $\beta$-dolabrin and 4-acetyltropolone showed strong antifungal activity against Pythium aphanidermatum IFO 32440, with minimum inhibitory concentration (MIC) at $6 \mu \mathrm{g} / \mathrm{ml}$.

Boyraz and Ozcan (2006) investigated inhibition of phytopathogenic fungi by essential oils, hydrosols, ground materials, and extract of summer savory (Satureja hortensis) growing wild in Turkey. The antifungal activities of all summer savory components on mycelial growth of Alternaria mali and $B$. cinerea were determined. All doses of extracts completely inhibited the mycelial growth of both fungi. Nguefack et al. (2008) reported that three essential oils extracted from Cymbopogon citrates, Ocimum gratissimum, and Thymus vulgaris are able to control seed-borne infection. The three essential oils applied as slurry controlled seed infection with a range of effectiveness of $48 \%$ to $100 \%$. Kordali et al. (2008) determined antifungal, phytotoxic, and insecticidal properties of the essential oil isolated from Turkish Origanum acutidens and its three components, carvacrol (9), thymol (10), and $p$-cymene (11). The antifungal assays showed that $O$. acutidens oil, carvacrol, and thymol completely inhibited the mycelial growth of 17 phytopathogenic fungi, and their antifungal effects were greater than that of the commercial fungicide benomyl. However, $p$-cymene possessed lower antifungal activity. The oil, carvacrol, and thymol completely inhibited the seed germination and seedling growth of Amaranthus retroflexus,
Chenopodium album, and Rumex crispus and also showed a potent phytotoxic effect against these plants. However, $p$ cymene did not show any phytotoxic effect. Furthermore, $O$. acutidens oil induced $68.3 \%$ and $36.7 \%$ mortality against Sitophilus granarius and Trivolium confusum adults, respectively.

Chang et al. (2008) reported antifungal activity against plant pathogenic fungi of essential oil and its constituents from Calocedrus macrolepis var. formosana Florin leaf. Tmuurolol and alpha-cadinol strongly inhibited the growth of $R$. solani and F. oxysporum, with $\mathrm{IC}_{50}$ of less than $50 \mu \mathrm{g}$ / $\mathrm{ml}$. These compounds also efficiently inhibited the mycelial growth of Colletotrichum gloeosporioides, Pestalotiopsis funerea, Ganoderma australe, and F. solani. Essential oils from 25 species of medicinal plants were tested as mycelial growth inhibitors against 6 important pathogenic and toxinogenic fungal species. All essential oils used in the agar dilution method evidently affected the growth of the 6 fungi (Zabka et al., 2009). Furthermore, Kordali et al. (2009) reported antifungal and herbicidal properties of essential oils and $n$-hexane extracts of Achillea gypsicola Hub-Mor. and A. biebersteinii (Asteraceae). The oils and hexane extracts were tested against 12 phytopathogenic fungi, and the oils were found to be more toxic than the hexane extracts. Of the fungi tested, mycelial growth of 11 fungi except $F$. graminearum was inhibited when treated with $A$. gypsicola oil. In addition, the extracts strongly increased the growth of $F$. equiseti and $F$. graminearum. Thobunluepop et al. (2009) screened antifungal activity of essential oils from Bergamot (Citrus hystrix) and tea tree (Melaleuca alternifolia) against economically important rice pathogenic fungi as $A$. brassicicola, A. flavus, Bipolaris oryzae, $F$. moniliforme, $F$. proliferatum, $M$. oryzae and $R$. solani. Tea tree oil at $2.0 \% \mathrm{v} / \mathrm{v}$ concentration showed the strongest inhibition of mycelial growth in F. monoliforme, F. proliferratum, B. oryzae, A. brassicicola, and A. flavus. Bergamot oil inhibited mycelial growth of all economically pathogenic fungi when applied at a $0.8 \% \mathrm{v} / \mathrm{v}$ concentration. However, it may not effectively control Magnaporthe oryzae and $R$. solani. Dan et al. (2010) reported that essential oils from Asarum heterotropoides var. mandshuricum inhibited the growth of the A. humicola, C. gloeosporioides, R. solani, and Phytophthora cactorum. These essential oils could be selected for developing lead compounds to control plant diseases.

\section{Fatty acids}

The potential of fatty acids in medical applications has been intensively investigated, but publications related to the biological activity of fatty acids against plant pathogens are relatively rare. Only few studies have been documented in 
this area: lauric acid (Walters et al., 2003) and some unsaturated fatty acids (Walters et al., 2004) have been shown to display inhibitory effects on several plant pathogens. Capric acid has been reported to possess the greatest cytotoxicity against Candida albicans (Bergsson et al., 2001), and (Z)-9-heptadecenoic acid has an inhibitory effect against Phytophthora infestans and Idriella bolleyi (Avis et al., 2001).

Hou and Forman (2000) reported antifungal activity of 10-hydroxystearic acid, 7S,10S-dihydroxy-8(E)-octadecenoic acid, and 12,13,17-trihydroxy-9(Z)-octadecenoic acid against Blumeria graminis f. sp. tritici, Puccinia recondita, Pseudocercosporella herpotrichoides, Septoria nodorum, M. oryzae, $R$. solani, P. infestans, and B. cinerea. Although 10-hydroxystearic acid and $7 S, 10 S$-dihydroxy-8(E)-octadecenoic acid showed no fungal disease control activity, 12,13,17-trihydroxy-9(Z)-octadecenoic acid did control plant pathogenic fungi, including $B$. graminis, $P$. recondita, $P$. infestans, and $B$. cinerea. Liu et al. (2008) investigated antifungal activities of 9 fatty acids (butyric acid (12), caproic acid (13), caprylic acid (14), capric acid (15), lauric acid (16), myristic acid (17), palmitic acid (18), oleic acid (19), and linoleic acid (20) against 4 phytopathogenic fungi, $A$. solani, $C$. lagenarium, $F$. oxysporum f. sp. cucumerinum, and $F$. oxysporum f. sp. lycopersici. Pot experiments showed that a mixture of palmitic and oleic acids enhanced the growth of seedlings of continuous-tomato and continuous-cucumber. With the exception of oleic acid, in the petri dish assay, all fatty acids tested were observed to inhibit mycelial growth of one or more tested fungi. In particular, saturated fatty acids, e.g., palmitic acid, showed stronger antifungal activity than unsaturated fatty acids, e.g., oleic acid.

Two polyacetylenic acids, octadeca-9,11,13-triynoic acid (21) and trans-octadec-13-ene-9,11-diynoic acid (22), isolated from Prunella vulgaris inhibited the growth of various plant pathogens, including $M$. oryzae, $R$. solani, $P$. infestans, $S$. sclerotiorum, F. oxysporum, and $P$. capsici (Yoon et al., 2010). In addition, these 2 compounds significantly suppressed the development of rice blast, tomato late blight, wheat leaf rust, and red pepper anthracnose, suggesting that fatty acids may be candidates for alternative approaches to the integrated control of phytopathogens.

\section{Phenolic compounds}

In recent years, a number of studies have been conducted on the antifungal activity of phenolic compounds found in medicinal plants. The compounds can be divided into simple phenolic compounds, flavones and related flavonoid glycosides, coumarins and derivatives, and anthraquinones.

Our research group reported in vivo antifungal activity against various plant pathogenic fungi of curcuminoids isolated from the rhizomes of Curcuma longa (Cho et al., $2006 \mathrm{a}$ and b). Three curcuminoids, curcumin (23), demethoxycurcumin (24), and bisdemethoxycurcumin (25), were purified from the methanol extract of $C$. longa rhizomes as antifungal agents. Among the three curcuminoids, demethoxycurcumin was the most active against both rice blast and tomato late blight, followed in order of curcumin and bisdemethoxycurcumin. In addition, the curcuminoids effectively inhibited the mycelial growth of three red pepper anthracnose pathogens, C. coccodes, C. gloeosporioides, and $C$. acutatum when applied in the range of $0.4-100 \mu \mathrm{g} /$ $\mathrm{ml}$. The curcuminoids also highly inhibited spore germination in $C$. coccodes, with bisdemethoxycurcumin the most active in this respect. Among the three curcuminoids, only demethoxycurcumin was effective in suppressing red pepper anthracnose caused by $C$. coccodes in a greenhouse test. However, they all exhibited no or little in vivo antifungal activity against other fungal pathogens responsible for rice sheath blight, tomato gray mold, wheat leaf rust, and barley powdery mildew.

Our research group also reported antifungal activity of the malabaricones from Myristica malabarica fruit rinds against phytopathogenic fungi. Three antifungal resorcinols were identified: malabaricones A (MA; 26), B (MB; 27), and $\mathrm{C}(\mathrm{MC} ; 28)$ (Choi et al., 2008). The three resorcinols inhibited mycelial growth in several plant pathogenic fungi, including $C$. coccodes, C. gloeosporioides, M. oryzae, and $R$. solani. The three compounds effectively reduced the development of rice blast, wheat leaf rust, and red pepper anthracnose. In addition, MC was highly active in reducing the development of tomato late blight.

Shin et al. (2007) investigated the antifungal activity of a kind of naphthoquinone, plumbagin (29), purified from leaves of Nepenthes ventricosa $\times$ maxima against phytopathogenic fungi, including $A$. alternata, $A$. niger, $B$. oryzae, F. oxysporum, P. capsici, R. solani, $R$. stolonifer var. stolonifer, and $S$. sclerotiorum. The compound exhibited antifungal activity against all the plant pathogenic fungi tested. The minimum inhibitory concentration values ranged from approximately 4.8 to $56.6 \mu \mathrm{g} / \mathrm{ml}$ against the 8 fungi listed above, with $R$. solani the most sensitive.

Chrysophanol (30), parietin (31), and nepodin (32) isolated from $R$. crispus rhizomes specifically reduced the development of barley and cucumber powdery mildews (Choi et al., 2004). The concentrations required for 50\% disease control against barley powdery mildew caused by B. graminis f. sp. hordei were $4.7 \mu \mathrm{g} / \mathrm{ml}, 0.48 \mu \mathrm{g} / \mathrm{ml}$, and $20 \mu \mathrm{g} / \mathrm{ml}$ for chrysophanol, parietin, and nepodin, respectively. Chrysophanol $(100 \mu \mathrm{g} / \mathrm{ml})$ and nepodin $(400 \mu \mathrm{g} / \mathrm{ml})$ suppressed cucumber powdery mildew which is caused by Podosphaera xanthii more effectively than the fungicides fenarimol $(30 \mu \mathrm{g} / \mathrm{ml})$ and polyoxin $\mathrm{B}(100 \mu \mathrm{g} / \mathrm{ml})$ under 
glasshouse conditions. Parietin ( 30 and $10 \mu \mathrm{g} / \mathrm{ml})$ reduced the development of cucumber powdery mildew as efficiently as fenarimol $(30 \mu \mathrm{g} / \mathrm{ml})$ and more effectively than polyoxin B $(100 \mu \mathrm{g} / \mathrm{ml})$. Now several products containing chrysophanol and parietin are commercially available as ecofriendly organic agro-materials in Korea.

Dehydro- $\alpha$-lapachone (33) isolated from Catalpa ovata stems showed a strong antifungal activity against plant pathogenic fungi (Cho et al., 2006c). It completely inhibited the mycelial growth of B. cinerea, C. acutatum, C. gloeosporioides, M. oryzae, and P. ultimum. It also controlled the development of rice blast, tomato late blight, wheat leaf rust, barley powdery mildew, and red pepper anthracnose.

Decursin (34) and decursinol angelate (35) isolated from Angelica gigas effectively control rice blast via the inhibition of spore germination, rather than mycelial growth, in $M$. oryzae (Yoon et al., 2011a). In addition, decursinol angelate reduced the development of wheat leaf rust and red pepper anthracnose (Yoon et al., 2011b). The three lignans erythroaustrobailignan-6 (EA6; 36), meso-dihydroguaiaretic acid (MDA; 37), and nectandrin-B (NB; 38) from M. fragrans displayed both antifungal and antibacterial activities (Cho et al., 2007). In vitro antimicrobial activity of the three lignans varied according to compound and target species. $A$. alternata, C. coccodes, C. gloeosporioides, M. oryzae, Agrobacterium tumefaciens, Acidovorax konjaci, and Burkholderia glumae were relatively sensitive to the three lignans. In vivo, all three compounds effectively suppressed the development of rice blast and wheat leaf rust. In addition, EA6 and NB were highly active against the development of barley powdery mildew and tomato late blight, respectively. Both MDA and NB also moderately inhibited the development of rice sheath blight. Choi et al. (2009) reported effects of neolignans from the stem bark of Magnolia obovata on plant pathogenic fungi. Four neolignans from stem bark of M. obovata were identified as magnolol (39), honokiol (40), 4-methoxyhonokiol (41), and obovatol (42). Magnolol and honokiol showed similar in vivo antifungal spectra against 7 plant diseases tested; both compounds effectively suppressed the development of rice blast, tomato late blight, wheat leaf rust, and red pepper anthracnose. 4Methoxyhonokiol and obovatol were highly active against only rice blast and wheat leaf rust, respectively.

\section{Alkaloids}

Pipernonaline (43), a piperidine alkaloid derived from long pepper (Piper longum), was reported to control the development of plant diseases caused by M. oryzae, $R$. solani, $B$. cinerea, $P$. infestans, $P$. recondite, and $B$. graminis. It showed a potent fungicidal activity against $P$. recondite, with $91 \%$ and $80 \%$ control values at concentrations of $0.5 \mu \mathrm{g} / \mathrm{ml}$ and $0.25 \mu \mathrm{g} / \mathrm{ml}$, respectively.

Zhou et al. (2003) reported that among fifiteen steroidal alkaloids from Veratrum taliense the verazine-type (veramitaline, stenophylline B, stenophyllin B-3-O- $\beta$-D-glucopyranoside, and veramiline-3- $O-\beta-\mathrm{D}$-glucopyranoside) and jerveratrum-type (jervine, jervine-3-O- $\beta$-D-glucopyranoside) alkaloids exhibited strong antifungal activities against the phytopathogenic fungus $P$. capsici, with MICs of 160, 120, $160,80,80$, and $120 \mu \mathrm{g} / \mathrm{ml}$, respectively. Two alkaloids, Dcalycanthin (44) and L-folicanthine (45), isolated from the seeds of Chimonanthus praecox showed significant inhibitory activity against five plant pathogenic fungi, $E x$ serohilum turcium, B. maydis, A. solani, S. sderotiorum, and $F$. oxysportium (Zhang et al., 2006). Singh et al. (2008) reported the antifungal activity of securinine (46) against some plant pathogenic fungi: A. alternata, A. brassicae, $A$. brassicicola, Curvularia lunata, C. maculans, C. pallenscens, C. musae, Helminthosporium echinoclova, and H. spiciferum.

\section{Glycosides}

Two sulfated triterpene glycosides, hemoiedemosides A (47) and B (48), from the Patagonian sea cucumber Hemoiedema spectabilis exhibited considerable antifungal activity against the phytopathogenic fungus Cladosporium cucumerinum. On the other hand, the semisynthetic desulfated hemoiedemoside A (47) was less active than two natural compounds hemoiedemosides A and B (Chludil et al., 2002). Saha et al. (2010) reported antifungal activity of triterpenic saponins from Sapindus mukorossi and Diploknema butyracea against phytopathogenic fungi. D. butyracea saponins exhibited significant antifungal activity against three fungi $\left(\mathrm{ED}_{50} 230\right.$ $455 \mu \mathrm{g} / \mathrm{ml}$ ), whereas $S$. mukorossi saponin was effective against two fungi $\left(\mathrm{ED}_{50} 181-407 \mu \mathrm{g} / \mathrm{ml}\right)$.

Pregnane glycosides from Cynanchum wilfordii are highly effective in reducing the development of powdery mildews (Yoon et al., 2011c). Among the six pregnane glycosides, three caudatin glycosides $(\mathbf{4 9}, \mathbf{5 2}$, and $\mathbf{5 4})$ showed stronger antifungal activities than polyoxin $\mathrm{B}$ or the three kidjoranine glycosides $(\mathbf{5 0}, \mathbf{5 1}$, and 53). A wettable powder-type formulation of the ethyl acetate extract from $C$. wilfordii roots prohibited the development of barley powdery mildew in growth chamber conditions and strawberry powdery mildew caused by Sphaerotheca humuli under greenhouse conditions. Our research group is currently developing a botanical fungicide for the environmentally benign control of powdery mildews.

\section{Conclusions}

The abuse and misuse of synthetic pesticides has caused environmental contamination and toxicity to living organisms. 
This has necessitated the use of ecofriendly biopesticides, and plant-derived substances are extensively available for developing botanical fungicides. Up to the present, a number of plant metabolites with various skeletons have been reported to have antifungal and antibacterial activities. Although only some botanical fungicides have been commercialized and their market share is very small, many products will be developed in the future because of intensive research on this topic. Compared to plant-derived compounds that show insecticidal activity, fungicidal compounds are recognized to have relatively low or little toxicity, increasing the chance of success for the development of botanical fungicides by using plant-derived metabolites. Therefore, plant-derived metabolites are expected to remain as essential tools for plant disease management. Moreover, they will continue to play a central role in increasing yields and improving quality in crops worldwide in the future. In addition, they will play an important role in reducing environmental pollution in agricultural ecosystems. Further studies will be required to investigate their cost, applicability, safety, and phytotoxicity against crops as potential botanical fungicides.

\section{Acknowledgments}

This study was performed with the support of the Cooperative Research Program for Agricultural Science \& Technology Development (Project No.: 200901OFT102966197), Rural Development Administration, Republic of Korea.

\section{References}

Avis, T. J. and Belanger, R. R. 2001. Specificity and mode of action of the antifungal fatty acid cis-9-heptadecenoic acid produced by Pseudozyma flocculosa. Appl. Environ. Microbiol. 67:956-960.

Bergsson, G., Arnfinnsson, J., Steingrimsson, O. and Thormar, H. 2001. In vitro killing of Candida albicans by fatty acids and monoglycerides. Antimicrob. Agents Ch. 45:3209-3212.

Boyraz, N. and Ozcan, M. 2006. Inhibition of phytopathogenic fungi by essential oil, hydrosol, ground material and extract of summer savory (Satureja hortensis L.) growing wild in Turkey. Int. J. Food Microbiol. 107:238-242.

Chang, H.-T., Cheng, Y.-H., Wu, C.-L., Chang, S.-T., Chang, T.-T. and Su, Y.-C. 2008. Antifungal activity of essential oil and its constituents from Calocedrus macrolepis var. formosana Florin leaf against plant pathogenic fungi. Bioresource Technol. 99:622-6270.

Cheng, S. S., Liu, J. Y., Chang, E. H. and Chang, S. T. 2008. Antifungal activity of cinnamaldehyde and eugenol congeners against wood-rot fungi. Bioresource Technol. 99:5145-5149.

Chludil, H. D., Muniain, C. C., Seldes, A. M. and Maier, M. S. 2002. Cytotoxic and antifungal triterpene glycosides from the
Patagonian sea cucumber Hemoiedema spectabilis. J. Nat. Prod. 65:860-865.

Cho, J.-Y., Choi, G. J., Lee, S.-W., Jang, K. S., Lim, H. K., Lim, C. H., Lee, S. O., Cho, K. Y. and Kim, J.-C. 2006a. Antifungal activity against Collectotrichum spp. of curcuminoids isolated from Curcuma longa L. rhizomes. J. Microbiol. Biotechnol. $16: 280-285$.

Cho, J.-Y., Choi, G. J., Lee, S.-W., Lim, H. K., Jang, K. S., Lim, C. H., Cho, K. Y. and Kim, J.-C. 2006b. In vivo antifungal activity against various plant pathogenic fungi of curcuminoids isolated from the rhizomes of Curcuma longa. Plant Pathol. J. 22:94-96.

Cho, J.-Y., Choi, G. J., Son, S. W., Jang, K. S., Lim, H. K., Lee, S. O., Sung, N. D., Cho, K. Y. and Kim, J.-C. 2007. Isolation and antifungal activity of lignans from Myristica fragrans against various plant pathogenic fungi. Pest Manag. Sci. 63:935-940.

Cho, J.-Y., Kim, H. Y., Choi, G. J., Jang, K. S., Lim, H. K., Lim, C. H., Cho, K. Y. and Kim, J.-C. 2006c. Dehydro- $\alpha$-lapachone isolated from Catalpa ovata stems: activity against plant pathogenic fungi. Pest Manag. Sci. 62:414-418.

Choi, G. J., Lee, S.-W., Jang, K. S., Kim, J.-S., Cho, K. Y. and Kim, J.-C. 2004. Effects of chrysophanol, parietin, and nepodin of Rumex crispus on barley and cucumber powdery mildews. Crop Prot. 23:1215-1221.

Choi, N. H., Choi, G. J., Jang, K. S., Choi, Y. H., Lee, S. O., Choi, J. E. and Kim, J.-C. 2008. Antifungal activity of the methanol extract of Myrisitica malabarica fruit rinds and the active ingredients malabaricones against phytopathogenic fungi. Plant Pathol. J. 24:317-321.

Choi, N. H., Choi, G. J., Min, B.-S., Jang, K. S., Choi, Y. H., Park, M. S., Choi, J. E., Bae, K. and Kim, J.-C. 2009. Effects of neolignans from the stem bark of Magnolia obovata on plant pathogenic fungi. J. Appl. Microbiol. 106:2057-2063.

Copping, L. G. 2004. The Manual of Biocontrol Agents, $3^{\text {rd }}$ Ed. BCPC Publications, Alton, Hants, UK, pp. 702.

Copping, L. G. and Menn, J. J. 2000. Biopesticides: a review of their action, applications and efficacy. Pest Manag. Sci. 56:651-676.

Dan, Y., Liu, H.-Y., Gao, W.-W. and Chen, S.-L. 2010. Activities of essential oils from Asarum heterotropoides var. mandshuricum against five phytopathogens. Crop Prot. 29:295-299.

Edris, A. E. and Farrag, E. S. 2003. Antifungal activity of peppermint and sweet basil essential oils and their major aroma constituents on some plant pathogenic fungi from the vapor phase. Nahrung. 47:117-121.

Hou, C. T. and Forman, R. J. 2000. Growth inhibition of plant pathogenic fungi by hydroxyl fatty acids. J. Ind. Microbiol. Biot. 24:275-276.

Khan, M. S. and Ahmad, I. 2011. In vitro antifungal, anti-elastase and anti-keratinase activity of essential oils of Cinnamomum-, Syzygium- and Cymbopogon-species against Aspergillus fumigates and Trichophyto rubrum. Phytomedicine 19:48-55.

Konstantinidou-Doltsinis, S., Markellou, E., Kasselaki, A.-M., Fanouraki, M. N., Koumaki, C. M., Schmitt, A., Liopa-tsakalidis, A. and Malathrakis, N. E. 2006. Efficacy of Milsana, a formulated plant extract from Reynoutria sachalinensis, 
against powdery mildew of tomato (Leveillula taurica). BioControl 51:375-392.

Kordali, S., Cakir, A., Akcin, T. A., Mete, E., Akcin, A., Aydin, T. and Kilic, H. 2009. Antifungal and herbicidal properties of essential oils and $n$-hexane extracts of Achillea gypsicola HubMor. and Achillea biebersteinii Afan. (Asteraceae). Ind. Crop Prod. 29:562-570.

Kordali, S., Cakir, A., Ozer, H., Cakmakci, R., Kesdek, M. and Mete, E. 2008. Antifungal, phytotoxic and insecticidal properties of essential oil isolated Turkish Origanum acutidens and its three components, carvacrol, thymol and $p$-cymene. Bioresource Technol. 99:8788-8795.

Kosina, P., Gregorova, J., Gruz, J., Vacek, J., Kolar, M., Vogel, M., Roos, W., Naumann, K., Simanek, V. and Ulrichova, J. 2010. Phytochemical and antimicrobial characterization of Macleaya cordata herb. Fitoterapia 81:1006-1012.

Liangbin, H., Hongbo, L., Junliang, S. and Zeng, J. 2012. Effect of laminarin on Aspergillus Flavus growth and aflatoxin production. Adv. Mat. Res. 342:1168-1171.

Liu, H., Wang, J., Zhao, J., Lu, S., Wang, J., Jiang, W., Ma, Z. and Zhou, L. 2009. Isoquinoline alkaloids from Macleaya cordata active against plant microbial pathogens. Nat. Prod. Commun. 4:1557-1560.

Liu, S., Ruan, W., Li, J., Xu, H., Wang, J., Gao, Y. and Wang, J. 2008. Biological control of phytopathogenic fungi by fatty acids. Mycopathologia 166:93-102.

Morita, Y., Matsumura, E., Okabe, T., Fukui, F., Ohe, T., Ishida, N. and Inamori, Y. 2004. Biological activity of $\beta$-dolabrin, $\gamma$ thujaplicin, and 4-acetyltropolone, hinokitiol-related compounds. Biol. Pharm. Bull. 27:1666-1669.

Nguefack, J., Leth, V., Lekagne Dongmo, J. B., Torp, J., Amvam Zollo, P. H. and Nyasse, S. 2008. Use of three essential oils as seed treatments against seed-born fungi of rice (Oryza sativa L.). American-Eurasian J. Agric. Environ. Sci. 4:554-560.

Reglinski, T. 2009. Disease control in crops: Biological and environmentally friendly approaches. Chapter 4 . Induced resistance for plant disease control, ed. by D. Walters, doi: 10 . 1002/9781444312157. Wiley-Blackwell, Oxford, UK.

Saha, S., Walia, S., Kumar, J. and Parmar, B. S. 2010. Structurebiological activity relationships in triterpenic saponins: the relative activity of protobassic acid and its derivatives against plant pathogenic fungi. Pest Manag. Sci. 66:825-831.

Shin, K.-S., Lee, S. and Cha, B. 2007. Antifungal activity of plumbagin purified from leaves of Nepenthes ventricosa $\mathrm{x}$ maxima against phytopathogenic fungi. Plant Pathol. J. 23:113-115.

Singh, A. K., Pandey, M. B., Singh, S., Singh, A. K. and Singh, U. P. 2008. Antifungal activity of securinine against some plant pathogenic fungi. Mycobiology 36:99-101.
Soundharrajan, R. S., Belusamy, R., Ramasamy, R., Selladurai, M. and Srinivasan, N. 2003. Antifungal activity of some essential oils. J. Agric. Food Chem. 51:7596-7599.

Thobunluepop, P., Udomsilp, J., Piyo, A. and Khengkhan, P. 2009. Screening for the antifungal activity of essential oils from bergamot oil (Citrus hystrix DC.) and tea tree oil (Melaleuca alternifolia) against economically rice pathogenic fungi: A driving force of organic rice cv. KDML 105 production. As. J. Food Ag-Ind. Special Issue: S374-S380.

Walters, D., Raynor, L., Mitchell, A., Walker, R. and Walker, K. 2004. Antifungal activities of four fatty acids against plant pathogenic fungi. Mycopathologia 157:87-90.

Walters, D. R., Walker, R. L. and Walker, K. C. 2003. Lauric acid exhibits antifungal activity against plant pathogenic fungi. $J$. Phytopahol. 151:228-230.

Wang, S.-Y., Chen, P.-F. and Chang, S.-T. 2005. Antifungal activities of essential oils and their constituents from indigenous cinnamon (Cinnamomum osmophloeum) leaves against wood decay fungi. Bioresource Technol. 96:813-818.

Yoon, M.-Y., Choi, G. J., Choi, Y. H., Jang, K. S., Park, M. S., Cha, B. and Kim, J.-C. 2010. Effect of polyacetylenic acids from Prunella vulgaris on various plant pathogens. Lett. Appl. Microbiol. 51:511-517.

Yoon, M.-Y., Kim, Y. S., Ryu, S. Y., Choi, G. J., Choi, Y. H., Jang, K. S., Cha, B., Han, S.-S. and Kim, J.-C. 2011a. In vitro and in vivo antifungal activities of decursin and decursinol angelate isolated from Angelica gigas against Magnaporthe oryzae, the causal agent of rice blast. Pest Biochem. Physiol. 101:118-124.

Yoon, M.-Y., Kim, Y. S., Choi, G. J., Jang, K. S., Choi, Y. H., Cha, B. and Kim, J.-C. 2011b. Antifungal activity of decursinol angelate isolated from Angelica gigas against Puccinia recondita. Res. Plant Dis. (in Korean) 7:25-31.

Yoon, M.-Y., Choi, N. H., Min, B. S., Choi, G. J., Choi, Y. H., Jang, K. S., Han, S.-S., Cha, B. and Kim, J.-C. 2011c. Potent in vivo antifungal activity against powdery mildews of pregnane glycosides from the roots of Cynanchum wilfordii. $J$. Agric. Food Chem. 59:12210-12216.

Zabka, M., Pavela, R. and Slezakova, L. 2009. Antifungal effect of Pimenta dioica essential oil against dangerous pathogenic and toxinogenic fungi. Int. Crops and Products 30:250-253.

Zhang, J. F., Li, Y. B., Li, C. L. and Jiang, J. Q. 2006. Studies on chemical constituents in root tuber of Cynanchum auriculatum. Zhongguo Zhong Yao Za Zhi 31:814-816.

Zhou, C.-X., Liu, J.-Y., Ye, W.-C., Liu, C.-H. and Tang, R.-X. 2003. Neoverataline A and B, two antifungal alkaloids with a novel carbon skeleton from Veratrum taliense. Tetrahedron 59:5743-5747. 